\title{
A prospective observational study of human factors, adverse events, and patient outcomes in surgery for pediatric cardiac disease
}

\author{
Paul Barach, MD, MPH, ${ }^{a}$ Julie K. Johnson, MSPH, PhD, ${ }^{\mathrm{b}}$ Asima Ahmad, BS, ${ }^{\mathrm{b}}$ Cynthia Galvan, MD, ${ }^{\mathrm{b}}$ Agnes Bognar, MD, MBA, \\ Robert Duncan, PhD, ${ }^{\mathrm{d}}$ Joanne P. Starr, MD, ${ }^{\mathrm{e}}$ and Emile A. Bacha, $\mathrm{MD}^{\mathrm{f}}$
}

\begin{abstract}
Objective: To explore the impact of human factors on intraoperative adverse events and compensation mechanisms in pediatric cardiac surgery.

Methods: Prospective observations of pediatric cardiac surgical procedures were conducted. Patient complexity scores were calculated and outcomes recorded. The process of care was divided into epochs. Events were extracted and coded into compensated or uncompensated major and minor adverse events. Linear regression and analysis of variance were used to analyze the relationships between epochs, complexity, adverse events, and outcome. Patient-specific and procedure-specific variables were tested in a forward stepwise logistic regression as predictors of cases with 1 or more major adverse events.
\end{abstract}

Results: One hundred two patients undergoing pediatric cardiac surgery were observed. An average of 1.2 (range 0-6) major adverse events occurred per case. The most common type of major adverse event was cardiovascular, and most occurred during the surgery/postbypass epoch. Cognitive compensation was the most common compensation mechanism for major adverse events. An average of 15.3 minor adverse events occurred per case. Minor adverse events occurred frequently during the surgery/bypass epoch and related to communication and coordination failures. Higher case complexity, longer surgery duration, and higher number of major adverse events per patient correlated with death compared with other outcome groups $(P<.01)$. Case complexity $(P<.01)$ and surgery duration $(P<.05)$ were both significant predictors of major adverse events.

Conclusions: Pediatric cardiac surgery is an ideal model to study the coordinated efforts of team members in a complex organizational structure. Adverse events occurred routinely during pediatric cardiac surgery and were mostly compensated. Case complexity was a significant predictor of major adverse events. The number of major adverse events per patient correlated with clinical outcomes.

Human factors research on team decision-making in complex task environments is of extreme relevance to surgical team performance. The operating room environment greatly affects and shapes surgical outcomes. ${ }^{1-3}$ Factors that influence the team's effectiveness include the performance of individual team members, the equipment they use, established care processes and procedures, and the underlying organizational and cultural factors. ${ }^{4}$ Recently, action science and ethnography methods have been applied in acute care settings to assess the impact of human factors on patient outcomes. $^{2,5-7}$ Pediatric cardiac surgery (PCS) in particular,

From the Department of Anesthesia, Utrecht Medical Center, Utrecht, The Netherlands, and the Department of Anesthesia, College of Medicine and Public Health, University of South Florida, Tampa, Fla ${ }^{\text {a }}$; the Department of Medicine, The University of Chicago, Chicago, $\mathrm{Ill}^{\mathrm{b}}$; the Departments of Anesthesiology ${ }^{\mathrm{c}}$ and Biostatistics, ${ }^{\mathrm{d}}$ University of Miami, Miami, Fla; the Department of Cardiac Surgery, Children's Hospital of New Jersey, Newark, $\mathrm{NJ}^{\mathrm{e}}$; and Department of Cardiac Surgery, Children's Hospital Boston and Harvard Medical School, Boston, Mass. ${ }^{\mathrm{f}}$

Research supported by a grant from the American Heart Association, award number $0330274 \mathrm{~N}$.

Supported by the Children's Heart Foundation.

Received for publication Jan 1, 2008; revisions received Feb 26, 2008; accepted for publication March 23, 2008.

Address for reprints: Emile A. Bacha, MD, Cardiac Surgery, Children's Hospital Boston, Harvard Medical School, 300 Longwood Ave, Boston, MA 02115 (E-mail: emile.bacha@cardio.chboston.org).

J Thorac Cardiovasc Surg 2008;136:1422-8

$0022-5223 / \$ 34.00$

Copyright (c) 2008 by The American Association for Thoracic Surgery

doi:10.1016/j.jtcvs.2008.03.071 a specialty with very low error tolerance, embodies the characteristics of complex microsystems. ${ }^{1,8-10}$ It encompasses many complex procedures that are dependent on a sophisticated organizational structure, coordinated efforts of multiple individuals, and high levels of cognitive and technical performance. ${ }^{11}$ Several factors have been linked to poor outcomes in PCS, including institution and surgeon-specific volumes, ${ }^{12,13}$ complexity of cases, ${ }^{14}$ and systems failures. ${ }^{5}$

The primary aim of this study was to explore the impact of intraoperative human factors and adverse events on surgical performance and patient outcomes in PCS. A secondary aim was to look at adverse events compensation mechanisms.

\section{METHODS}

The operating room was considered a "microsystem", - a small, welldefined front-line unit providing care for a specific patient population. ${ }^{8} \mathrm{~A}$ pre-study process mapping defined the boundaries of the clinical microsystem that was to be studied. ${ }^{9,10}$ The process of care was divided into 7 epochs based on extensive observations and an iterative process (Figure 1): (1) preoperative/transport to operating room; (2) anesthesia induction; (3) surgery before bypass; (4) surgery bypass/repair; (5) surgery after bypass; (6) transport to intensive care unit (ICU); (7) hand off to ICU team.

Two observers performed real-time prospective observations of the PCS team from the inception of anesthesia to the patient hand-off in the ICU. Training for the observers included in-depth directed study of cardiac surgery theory and literature, watching videotaped PCS procedures, detailed discussions on human observational methods, and informal testing (with E.A.B., P.B., and J.K.J.). ${ }^{15}$ Full institutional review board approval was attained. Written consent was acquired from all PCS team members, parents, 


\author{
Abbreviations and Acronyms \\ $\mathrm{CPB}=$ cardiopulmonary bypass \\ ICU = intensive care unit \\ HIPPA $=$ Health Insurance Portability and \\ Accountability Act \\ PCS = pediatric cardiac surgery
}

or guardians. Health Insurance Portability and Accountability Act (HIPAA) authorization was gained from parents or guardians. Data were de-identified on the basis of institutional review board IRB requirements and in compliance with HIPAA regulations.

The outcome scores were coded at discharge by a previously published 1 to 4 scale as follows: (1) uncomplicated hospital stay, (2) intubation more than 72 hours with mild morbidity, (3) prolonged intubation and major morbidity, and (4) death. ${ }^{16}$ Mortality was defined as any in-patient mortality or as outpatient mortality within 30 days of surgery. ${ }^{17}$ Clinical variables collected for each patient included age, weight, gestational age, sex, admission date, date of surgery, discharge date, length of stay, status at discharge and 30 days postoperatively, preoperative status such as need for intubation, inotropes, urgency of repair, operating room times, postoperative ventilation time, extubation date, and need for mechanical support. Clinical case complexity was measured by the comprehensive Aristotle risk assessment scoring system. ${ }^{14}$ The scoring tool stratifies on the basis of the potential for morbidity, mortality, and the anticipated technical difficulty of a given procedure.

Patients younger than 18 years were chosen randomly, but an effort was made to focus on neonates and patients with complex conditions. The surgeon wore a video head-camera so that observers could also follow the surgical steps. The observers created a handwritten observational tool to document the surgical flow. The field notes were transcribed by an independent party and later analyzed by the research team. Adverse events were defined as "unintended incidents in care that may result in adverse outcomes or may require additional care efforts to prevent adverse outcomes." 18 The events were extracted and coded according to immediate patient outcomes. Adverse events were classified as major or minor events (major event-may have serious consequences; minor events-not expected to cause serious consequences or break in surgical flow). ${ }^{16}$ Events were then further classified as compensated or uncompensated (compensation-appropriate action taken to offset the effect of adverse event).

Events were further categorized into each appropriate epoch and subdivided into the following clinical naturalistic categories: (1) blood products; (2) lines and line placement; (3) instruments (4) monitoring; (5) sterility and hygiene; (6) cardiopulmonary bypass (CPB); (7) bleeding; (8) ventilation; (9) technical/surgical issues; (10) communication; (11) medications (12) transport; (13) cognitive; (14) cardiovascular; and (15) transesophageal echocardiogram.

The following types of compensation were differentiated: (1) cognitive; (2) luck; (3) system (4) surgical-technical; and (5) monitoring. "Luck" was defined as a compensation occurring solely because the compensatory action happened to occur at the right time but without any explicit clinician reasoning. "System", was defined as the policies and procedures already in place. The videotapes were reviewed when necessary to corroborate observational data. The data were later analyzed independently by a pediatric cardiac surgeon and a cardiac anesthesiologist. Patients were followed up prospectively throughout their hospital course by the observers. All data were documented in an Excel database.

\section{Statistical Analysis}

The data were analyzed for both descriptive and analytic statistics. We focused on identifying the relationships between the number of events, types of events, length of the epochs, timing of events with case complexity, and outcomes. $\chi^{2}$ Analyses, analysis of variance, and linear regression models were used to analyze relationships between length of the epochs, number of events per case, case complexity, and outcomes. Confidence intervals were measured when possible.

\section{RESULTS \\ Demographics}

Between September 2003 and January 2005, 431 pediatric cardiac operations were performed at the University of Chicago Children's Hospital, and 102 (24\%) patients were observed (735 hours of observation). The mean age was 499 days (range 1 day-15 years). The group included 29 $(28 \%)$ neonates and 43 infants. CPB was used in 84 $(82 \%)$ patients. The median Aristotle complexity comprehensive score was 12.6 (range 3.5-24.5). A total of 1315 adverse events were noted. The study group had a 30-day and hospital mortality rate of $3.9 \%$ and $6.9 \%(n=7)$, respectively. The mortality rate was higher than that of the entire operated cohort during the same time period $(3.9 \%$ vs $2.5 \%$ ).

\section{Major Events (Table 1)}

A median of 1.1 major events (range 0-6) occurred per case. The majority of events $(43 \%)$ occurred during the postbypass epoch, including cardiovascular adverse events $(56 \%)$ and bleeding adverse events (62\%) (Figure 1). The most common type of event was related to the cardiovascular system $(20 \%)$, followed by an airway or pulmonary event $(14 \%)$ (Figure 2). Cognitive compensation was the most common type of compensation (35\%) (Figure 3). Two major events were uncompensated: a carotid laceration resulting from attempts at internal jugular line placement and that left no lasting harm, and a malignant ventricular tachyarrhythmia that was unresponsive to conservative measures and eventually required emergency extracorporeal membrane oxygenator support. The analysis of variance demonstrated that significantly higher case complexity, longer surgery time, and higher number of major events per case were correlated with a death outcome $(P<.05)$.

\section{Minor Events (see Table 1)}

A median of 18.3 minor events (range 2-54) occurred per case, most often during CPB (32\%) (Figure 1). In addition, $36 \%$ of communication problems and $31 \%$ of instrumentation difficulties also occurred during the $\mathrm{CPB}$ period. The most common type of minor events was communication failures $(29 \%)$ (Figure 2$)$. The most common type of compensatory mechanisms was system counterdefenses in $47 \%$ of events (Figure 3).

\section{Correlations}

The length of the surgical procedure ("surgery epoch") (mean 301 minutes; SD 101 minutes) correlated with case complexity $(r=0.83 ; P<.05)$, whereas neither the 
Process Flow

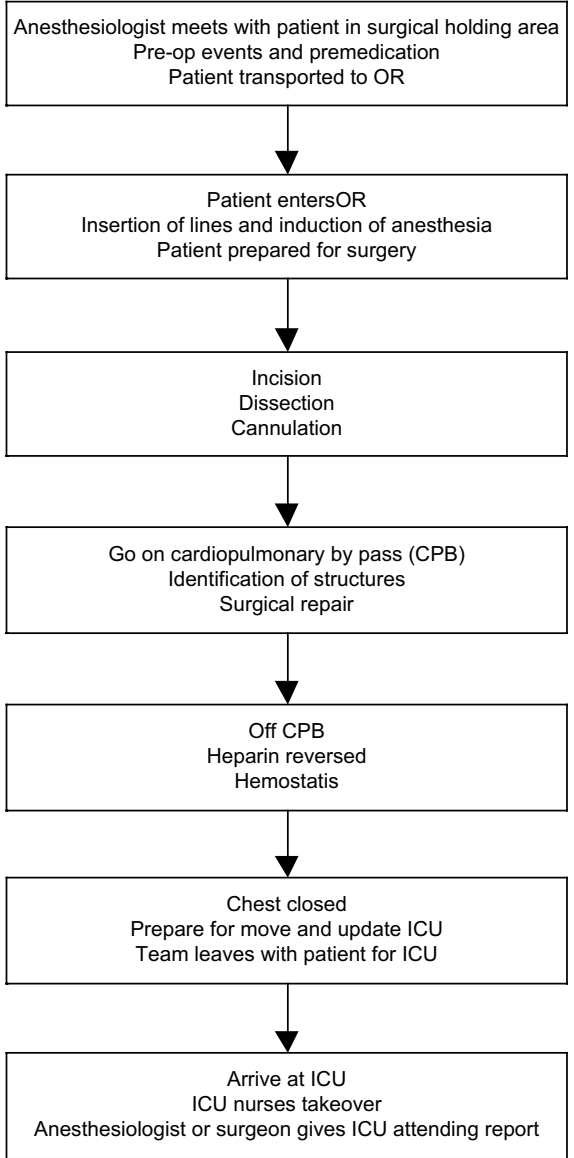

Domain

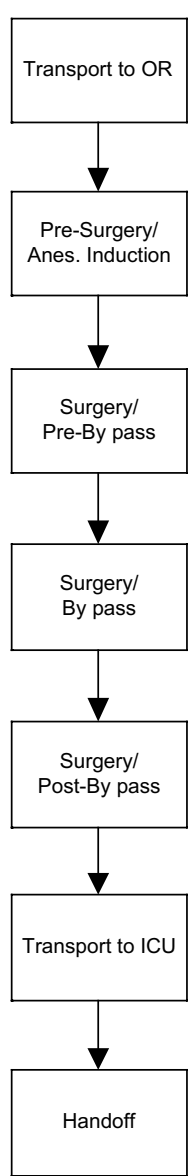

Major Events Minor Events

$(n=92) \quad(n=1223)$
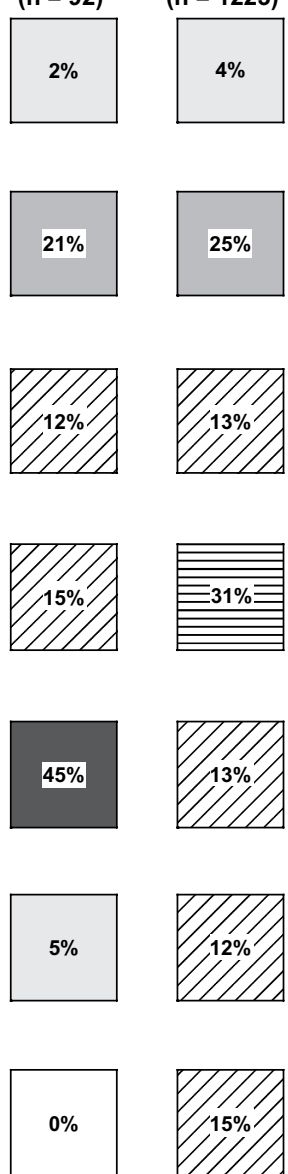

FIGURE 1. The process of care was divided into 7 epochs based on extensive observations and an iterative process. $O R$, operating room; $I C U$, intensive care unit.

" "anesthesia induction" time (mean $=74$ minutes; $\mathrm{SD}=24$ minutes) nor the "postoperative" (mean $=25$ minutes; $\mathrm{SD}=11$ minutes) epochs correlated with case complexity by analysis of variance.

Case complexity, longer surgery time, and higher number of major events per case correlated with outcome 4 (death) $(P<.05)$. The number of major events per case correlated with patient outcomes $(P<.05)$ and case complexity $(P<$ $.01)$.

The duration of surgery and the number of major events per case increased with case complexity. Case complexity was not significantly different between patients with type 2 or 3 outcomes (Table 2). Excluding non-CPB cases or using hospital mortality instead of 30-day mortality did not change the statistical results or their significance. There were no significant differences between different outcome groups in the number of minor events per case.

\section{Predictive Value of the Observation Data}

The complexity of the case (odds ratio $=1.29[1.05-$ 1.57]; $P=.0131$ ) and the surgery duration (odds ratio $=$
1.01 [1.00-1.02]; $P=.0475)$ were both significant predictors of major events.

\section{DISCUSSION}

The principal findings of this study were as follows:

1. Major and minor adverse events occurred regularly during PCS.

2. Case complexity and surgery duration were both significant predictors of major events.

3. The number of major events correlated with clinical outcomes.

4. Ninety-eight percent of major adverse events and $90 \%$ of minor events were compensated; however, compensation mechanisms were found to be more reactive than preventive.

Over the past few years, a plethora of solutions have been proposed to address the deficiencies in health care delivery. However, very few of these solutions have been evidencebased. Subsequently, there has been little impact on reducing patient harm, and a dearth of knowledge regarding the 

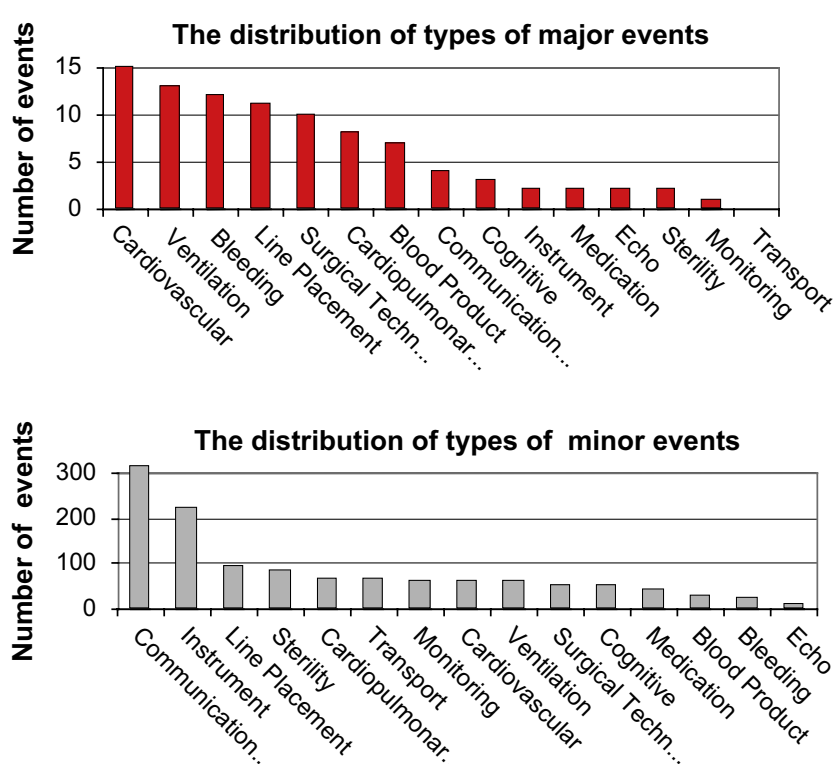

FIGURE 2. The distribution of types of major and minor events.

true incidence of adverse events exists. ${ }^{19}$ Several recent studies have demonstrated that the majority of hospital adverse events are related to an invasive or surgical procedure and occur predominantly during the intraoperative phase of the procedure. ${ }^{20}$ Extensive inquests into preventable deaths after PCS, such as the Manitoba Inquiry ${ }^{21}$ and the Bristol Royal Infirmary Inquiry, ${ }^{22}$ have revealed the influential impact of human factors and system issues on PCS outcomes. A landmark study by de Leval and colleagues ${ }^{16}$ investigated the role of human factors on surgical outcomes in PCS patients, specifically using the arterial switch operation as an example of complex, high-risk surgery. The identification of, and successful recovery from, major and minor adverse events was observed. The total numbers of minor and major events per case were both strong predictors of the probability of death and near miss. They found that, although proper compensation greatly reduced the risk of death, minor events go largely unnoticed by the operating room team and are therefore left uncompensated. ${ }^{16}$ A subsequent analysis of the same data suggested that minor events impede the operating room team's ability to compensate for future major events. $^{9}$

These findings, and the findings of Catchpole and associates, ${ }^{1}$ are entirely consistent with the present study, which is also heavily weighted toward complex cardiac repairs (as evidenced by a median Aristotle comprehensive score of 12.6) ${ }^{14,17}$ Given the complexity of the repairs selected by the study, it is not surprising that the majority of major adverse events (41/92 [44\%]) belonged to the cardiovascular system (cardiovascular, bleeding, surgical-technical, $\mathrm{CPB})$. Many of the major events were related to organizational accidents, which followed closely Reason, Carthey, and de Leval's model ${ }^{23}$ of latent elements in a microsystem predisposing teams to have major adverse events.

The epoch most laden with adverse events was by far the surgery/postbypass epoch, during which $45 \%$ of all major adverse events occurred. This vulnerable and unstable period begins with the aortic crossclamp release and is followed by weaning and separation from CPB. This can be seen as analogous to aviation's most event-laden periods, take-off and landing (also called the "glass cockpit," that is, all communications not related to takeoff and landing restricted below 10,000 feet). ${ }^{24}$ These results are also strikingly similar to a comparable study performed in adult cardiac surgery patients in which the majority of major adverse events occurred either during CPB or during the postbypass phase. ${ }^{25}$ These studies reinforce our understanding that this epoch is the most distraction-sensitive and human error-prone period in the intraoperative cardiac surgical process. Not surprisingly, the majority of instrument and device difficulties also occurred during the CPB period.

In contradistinction to the observational studies on the arterial switch operation, which found a high correlation between number of minor events and outcomes, ${ }^{16,26}$ we did not find a similar effect. This is most likely due to the fact that we were not studying one specific operation performed at many different hospitals, but rather a variety of
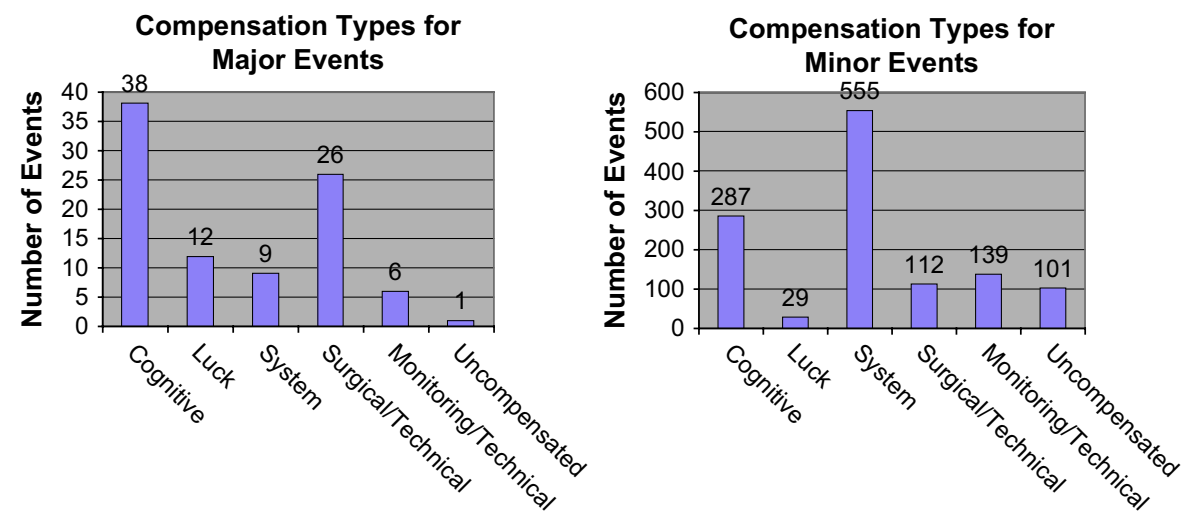

FIGURE 3. Compensation types for major and minor events. 
TABLE 1. Examples of major and minor adverse events

\begin{tabular}{|c|c|c|}
\hline Epoch & Major AE (appropriate category in parenthesis) & Compensation mechanism \\
\hline Transport to OR & $\begin{array}{l}\text { - Inadequate preop with possible harm had case proceeded } \\
\text { (Communication) }\end{array}$ & - System \\
\hline Presurgery/anesthesia induction & $\begin{array}{l}\text { - Accidental extubation while placing TEE probe (TEE) } \\
\text { - Carotid artery stick during internal jugular line placement } \\
\text { with major intrathoracic hematoma (Line placement) }\end{array}$ & $\begin{array}{l}\text { - Cognitive } \\
\text { - Uncompensated (noticed after sternotomy } \\
\text { and required repair on CPB) }\end{array}$ \\
\hline Surgery/prebypass & $\begin{array}{l}\text { - Lack of ventilation on partial bypass with alarms } \\
\text { silenced (Ventilation) } \\
\text { - Aortic laceration during redo sternotomy (Technical/surgical) }\end{array}$ & • Technical \\
\hline Surgery/bypass & $\begin{array}{l}\text { - Cap left off } \mathrm{O}_{2} \text { tank, resulting in no blood oxygenation for } \\
\text { first } 2 \text { minutes of bypass }(\mathrm{CPB}) \\
\text { - Pulmonary artery anastomosis stenotic (CV) }\end{array}$ & $\begin{array}{l}\text { - Cognitive (surgeon noticed dark } \\
\text { deoxygenated blood in arterial limb of } \\
\text { CPB system) } \\
\text { - Technical (redone) }\end{array}$ \\
\hline Surgery/postbypass & $\begin{array}{l}\text { - Excessive bleeding (Bleeding) } \\
\text { - Blood products not ready (Blood products) }\end{array}$ & $\begin{array}{l}\text { - Technical } \\
\text { - Luck (because none were needed } \\
\text { despite complex case) }\end{array}$ \\
\hline Transport to ICU & - $\mathrm{O}_{2}$ tank ran out (Transport) & • Monitoring \\
\hline
\end{tabular}

\begin{tabular}{lll}
\multicolumn{1}{c}{ Epoch } & \multicolumn{1}{c}{ Minor AE } & Compensation mechanism \\
\hline Transport to OR & $\bullet$ Wrong patient chart & $\bullet$ System \\
Presurgery/anesthesia induction & $\bullet$ Sterility during line placement & $\bullet$ Uncompensated \\
Surgery/prebypass & $\bullet$ Equipment problems (electrocautary) & $\bullet$ Monitoring \\
Surgery/bypass & $\bullet$ Coordination between surgeon and assistant & $\bullet$ Cognitive \\
Surgery/postbypass & $\bullet$ Communication breakdown & $\bullet$ System \\
Transport to ICU & $\bullet$ Delay in equipment (bed) availability & $\bullet$ Uncompensated \\
\hline
\end{tabular}

$A E$, Adverse event; $O R$, operating room; $T E E$, transesophageal echocardiogram; $C P B$, cardiopulmonary bypass; $C V$, cardiovascular; $I C U$, intensive care unit.

complex repairs in one hospital. The fact that a subsequent study of a mixture of cases by the same group in London yielded only a weak relationship between minor events and outcome further supports the generalizability of our findings. ${ }^{1}$ In the present study, most minor events occurred during the surgery/bypass epoch, followed closely by the presurgery/anesthesia induction epoch. The most common type of minor events was communication failures $(29 \%)$, $36 \%$ of which occurred during the CPB period and $26 \%$ during the anesthesia induction. The predominance of communication failures mirrors the findings of the Joint Comission on Accreditation of Healthcare Organizations (JCAHO) national sentinel event reporting program ${ }^{27}$ and also the findings of two other recent studies. ${ }^{2,4}$ This suggests an area in need of improvement, with greater attention paid to the nuances of communication modes during induction and $\mathrm{CPB}$ times.
Interestingly, we found that minor events were independent of case complexity and occurred in all cases. This is a unique and troubling finding. Minor events seemed to arise from a different dynamic that occurred in all cases, irrespective of case complexity, case duration, or seniority of team. The large number of minor events seems to indicate an environment awash with distractions, interruptions, and miscommunications. This again bears a striking resemblance to the adult cardiac surgery study reported by Wong and colleagues. ${ }^{25}$ The data suggest opportunities for clinical redesign of care as well as opportunities for team training. Focused team communication training, for example, has been shown to improve the subjective and objective reliability of communication exchanges. ${ }^{28}$

The compensation mechanisms differed for major and minor adverse events. For major adverse events, cognitive and surgical-technical compensation, rather than primary

TABLE 2. Outcome by case complexity, length of surgery, major events, and minor events (mean $\pm \mathrm{SE})$

\begin{tabular}{|c|c|c|c|c|c|}
\hline Outcome & $\mathbf{N}$ & Case complexity & Length of surgery (min) & $\begin{array}{c}\text { No of major } \\
\text { events per case }\end{array}$ & $\begin{array}{l}\text { No of minor } \\
\text { events per case }\end{array}$ \\
\hline 1 & 64 & $9.9 \pm(0.39)$ & $196.9 \pm(11.39)$ & $0.9 \pm(0.16)$ & $17.4 \pm(1.06)$ \\
\hline 2 & 20 & $13.8 \pm(0.88)$ & $198.9 \pm(19.34)$ & $1.1 \pm(0.25)$ & $20.2 \pm(2.47)$ \\
\hline 3 & 11 & $13.6 \pm(1.00)$ & $184.1 \pm(30.73)$ & $1.3 \pm(0.38)$ & $18.4 \pm(4.42)$ \\
\hline 4 & 7 & $19.5 \pm(1.52)$ & $367.2 \pm(28.12)$ & $2.7 \pm(0.89)$ & $21.1 \pm(6.54)$ \\
\hline
\end{tabular}

Higher case complexity, longer surgery time, and more major events per case correlated significantly with outcome 4 (death) as compared to other outcomes (analysis of variance). There was no significant difference in the number of minor events per case between different outcome groups. 


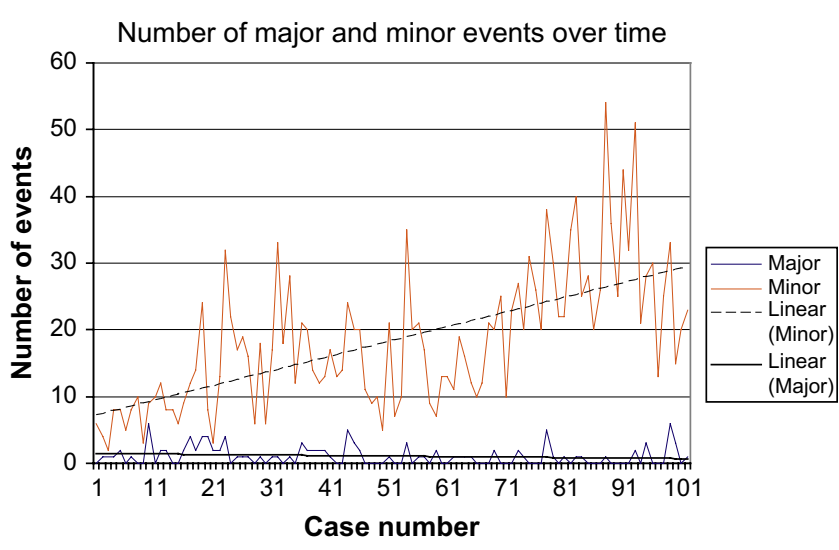

FIGURE 4. Number of major and minor events over time.

prevention or system measures, were the prevalent team practices ( $70 \%$ of all compensation). While surgical-technical compensation is inherent to any surgical procedure, the prevalence of cognitive compensation (41\%) implies that human factors play an important role in PCS outcomes. The system compensation mechanism was triggered in only $10 \%$ of cases, and "luck" was the main compensatory mechanism in $13 \%$. A system that relies heavily on cognitive prevention or on "luck" is inherently unreliable and dependent on external forces, such as surgeon fatigue, personal issues, and other extraneous factors. Interestingly, minor events compensatory mechanisms were mostly geared toward system compensation ( $45 \%$ of cases), suggesting that the systems that have been put in place as barriers against adverse events are not resilient enough to catch major adverse events. ${ }^{29}$

The number of major adverse events per case correlated significantly with hospital survival despite the fact that virtually all major events were compensated (or deemed to be acutely compensated by the study group). This would suggest that the compensatory mechanisms may not have been sufficient in preventing death, since ideally, perfect compensation would imply complete long-term recovery from an adverse event. Furthermore, compensation was most often reactionary in nature and not preventive or proactive, suggesting a definite role for improvement in clinical processes toward prevention.

\section{Limitations of this Study}

We recognize several limitations to the study. There are limitations to both human factors research and statistical analysis of performance assessment. The capture of observational data is by necessity subjective and observer-dependent and can suffer from interrater reliability as well as a sampling bias. ${ }^{3,15}$ Undoubtedly, many events, and especially those occurring behind the anesthetic curtain, might have been missed. However, identification of major adverse events remained stable throughout the course of the study, suggesting that the observers were able to pick up most if not all major adverse events (Figure 4). We calibrated our observer carefully, including using two observers early in the study to observe the same case, and found remarkably similar findings. On the other hand, the capture of minor events did go up as the study progressed, suggesting that the observers became increasingly familiar with the myriad of potential event enablers and were able to discern more adequately routine from nonroutine events. Observers were overseen by participating clinical personnel, possibly creating an inherent bias. The adverse event domains and compensation typology were developed on the basis of extensive clinical experience and in-depth knowledge of the cognitive psychology of human error and responses. It will benefit from further validation. The domains overlap, reflecting the complexity of the PCS environment. For example, a cognitive element is nearly always present even if the adverse event is strictly technical or monitoring related. In every case, we have tried to choose the most appropriate main compensation mechanism, which, although always determined by consensus, remains subjective by definition.

Finally, standardized training and calibration of observers would improve the data collection. More sophisticated and objective observational measures could be introduced in the operating room. ${ }^{30}$ Technical innovations, such as the remote analysis of surgical environment ${ }^{6}$ that allow real-time coding of specific communications and interactions, could evolve to capture a wider range of operative events. The creation of a computer tablet-based tool that allows for precise and fast data recording would undoubtedly facilitate observations. ${ }^{2}$ In the future, more sophisticated observation methods will help detect system vulnerabilities, recognize suboptimal team performance, and highlight the role of human factors on patient process and outcomes.

\section{References}

1. Catchpole KR, Giddings AE, de Leval MR, Peek GJ, Godden PJ, Utley M, et al. Identification of systems failures in successful paediatric cardiac surgery. Ergonomics. 2006;49:567-88.

2. Christian CK, Gustafson ML, Roth EM, Sheridan TB, Gandhi TK, Dwyer K, et al. A prospective study of patient safety in the operating room. Surgery. 2006;139. 159-73.

3. Thomas EJ, Peterson LA. Measuring errors and adverse events in health care J Gen Intern Med. 2003;18:61-7.

4. Elbardissi AW, Wiegmann DA, Dearani JA, Daly RC, Sundt TM. Application of the human factors analysis and classification system methodology to the cardiovascular surgery operating room. Ann Thorac Surg. 2007;83:1412-9.

5. de Leval MR, Francois K, Bull C, Brawn W, Spiegelhalter D. Analysis of a cluster of surgical failures: application to a series of neonatal arterial switch operations. J Thorac Cardiovasc Surg. 1994;107:914-24.

6. Guerlain S, Adams RB, Turrentine FB, Shin T, Guo H, Collins SR, et al. Assessing team performance in the operating room: development and use of a "blackbox" recorder and other tools for the intraoperative environment. $J$ Am Coll Surg. 2005;200:29-37.

7. Galvan C, Bacha EA, Mohr J, Barach P. Analysis of human factors during complex infant cardiac surgical repairs. Prog Pediatr Cardiol. 2005;20:13-20.

8. Mohr J, Batalden P, Barach P. Integrating patient safety into the clinical microsystem. Qual Saf Health Care. 2004;13(Suppl. 2):ii34-8.

9. Carthey J, de Leval MR, Reason JT. The human factor in cardiac surgery: errors and near misses in a high technology medical domain. Ann Thorac Surg. 2001;72: $300-5$. 
10. Barach P, Johnson JK. Understanding the complexity of redesigning care around the clinical microsystem. Qual Saf Health Care. 2006;15(Suppl. 1):i10-6.

11. Gallivan S, Davis KB, Stark JF. Early identification of divergent performance in congenital cardiac surgery. Eur J Cardiothoracic Surg. 2001;20:1214-9.

12. Hannan EL, Racz M, Kavey R, Quaegebeur JM, Williams R. Pediatric cardiac surgery: the effect of hospital and surgeon volume on in-hospital mortality. Pediatrics. 1998;101:963-9.

13. Spiegelhalter DJ. Mortality and volume of cases in paediatric cardiac surgery: retrospective study based on routinely collected data. BMJ. 2001;323:1-5.

14. Lacour-Gayet F, Clarke D, Jacobs J, Comas J, Daebritz S, Daenen W, et al. The Aristotle score: a complexity-adjusted method to evaluate surgical results. Eur J Cardiothorac Surg. 2004;25:911-24.

15. Carthy J. The role of structured observational research in health care. Qual Saf Health Care. 2003;12(Suppl. III):ii13-6.

16. de Leval MR, Carthey J, Wright DJ, Farewell VT, Reason JT. Human factors and cardiac surgery: a multicenter study. J Thorac Cardiovasc Surg. 2000;119(4 Pt 1):651-72.

17. Jacobs JP, Jacobs ML, Maruszewski B, Lacour-Gayet FG, Clarke DR, Tchervenkov CI, et al. Current status of the European Association for Cardio-Thoracic Surgery and The Society of Thoracic Surgeons Congenital Heart Surgery Database. Ann Thorac Surg. 2005;80:2278-84.

18. Kohn LT, Corrigan JM, Donaldson MS. To err is human. Building a safer health system. Committee on Quality of Healthcare in America. Institute of Medicine. Washington [DC]: National Academy Press; 2000.

19. Leape LL, Berwick DM. Five years after To Err Is Human: what have we learned? JAMA. 2005;293:2384-90.
20. Gawande AA, Zinner MJ, Studdert DM, Brennan TA. Analysis of errors by surgeons at three teaching hospitals. Surgery. 2003;133:614-21.

21. http://www.pediatriccardiacinquest.mb.ca/pdf/pcir_intro.pdf.

22. Walsh K, Offen N. A very public failure: lessons for quality improvement in healthcare organizations from the Bristol Royal Infirmary. Qual Health Care. 2001;10:250-6

23. Reason JT, Carthey J, de Leval MR. Diagnosing "vulnerable system syndrome": an essential prerequisite to effective risk management. Qual Health Care. 2001;10 (Suppl. 2):ii21-5.

24. Wiegmann DA, Shappell SA. Human error analysis of commercial aviation accidents: application of the Human Factors Analysis and Classification system (HFACS). Aviat Space Environ Med. 2001;72:1006-16.

25. Wong DR, Vander Salm TJ, Ali IS, Agnihotri AK, Bohmer RM, Torchiana DF. Prospective assessment of intraoperative precursor events during cardiac surgery. Eur J Cardiothorac Surg. 2006;29:447-55.

26. Solis-Trapala IL, Carthey J, Farewell VT, de Leval MR. Dynamic modelling in a study of surgical error management. Stat Med. 2007;26:5189-202.

27. Update: sentinel event statistics. Jt Comm Perspect. 2006;26:14-5.

28. Hamman WR. The complexity of team training: what we have learned from aviation and its applications to medicine. Qual Saf Health Care. 2004;13(Suppl. 1): i72-9.

29. Amalberti R, Auroy Y, Berwick D, Barach P. Five system barriers to achieving ultrasafe health care. Ann Intern Med. 2005;142:756-64.

30. Helmreich RI. On error management: lessons from aviation. BMJ. 2000;320: $781-5$. 